\title{
EDORIUM journals
}

www.edoriumjournals.com

\section{A case report of papular-purpuric gloves and socks syndrome: A manifestation of the parvovirus B19}

\author{
Inês Burmester, André Santa-Cruz, Julieta Ramalho, Maria João Regadas, \\ Paulo Gouveia, Guilherme Castro Gomes, Cristina Ângela, Narciso Oliveira, \\ Fernando Mota-Garcia, António Oliveira e Silva
}

\begin{abstract}
Introduction: The majority of parvovirus B19 infections are asymptomatic. In childhood, however, they may present as the fifth disease and in adults their manifestations can vary from mild, non-specific, cold-like symptoms to other forms of presentations. Papular-purpuric gloves and socks syndrome (PPGSS) is an uncommon form of parvovirus B19 infection, characterized by symmetric, pruriginous and painful erythema and edema of feet and hands. Generally, systemic symptoms are usually mild and dissemination to other body regions occurs in only $50 \%$ of the cases. The rash gradually progresses to petechiae and purpura delineating well demarcated "socks" and "gloves" on both feet and hands. The diagnosis is predominantly based on the clinical features. Serologic conversion is not considered as evidence of parvovirus B19 infection and histopathological findings from lesional skin are not specific. There are no definite antiviral drugs or vaccines against parvovirus. Patients with PPGSS require only symptomatic therapy.

Case Report: We report the case of a 30-year-old female with this characteristic erythema caused by the parvovirus B19. Nevertheless, this case is remarkable because the patient had significant systemic manifestations and an exuberant perineal and oropharyngeal involvement. Further, the erythema assumed a bullous expression that has not been so commonly reported. A biopsy was performed which was unspecific and the diagnosis was confirmed with the serology and molecular detection of the virus in blood sample as well as on mouth swab. Our patient needed treatment to control pain and pruritus, fever was self-limited.
\end{abstract}

Conclusion: A high index of suspicion is essential to diagnose patients with this syndrome. Early recognition can prevent unproductive measures and the good management of this infection.

International Journal of Case Reports and Images (IJCRI)

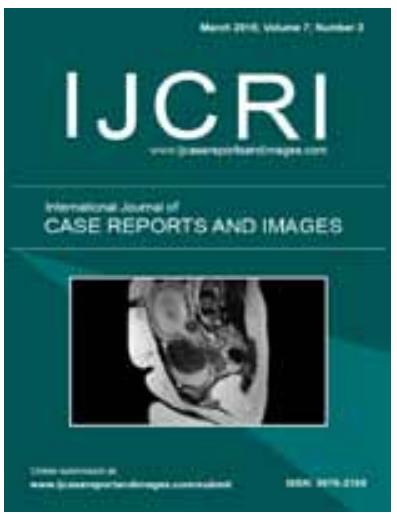

International Journal of Case Reports and Images (IJCRI) is an international, peer reviewed, monthly, open access, online journal, publishing high-quality, articles in all areas of basic medical sciences and clinical specialties.

Aim of IJCRI is to encourage the publication of new information by providing a platform for reporting of unique, unusual and rare cases which enhance understanding of disease process, its diagnosis, management and clinico-pathologic correlations.

IJCRI publishes Review Articles, Case Series, Case Reports, Case in Images, Clinical Images and Letters to Editor.

Website: www.ijcasereportsandimages.com 


\title{
A case report of papular-purpuric gloves and socks syndrome: A manifestation of the parvovirus B19
}

\author{
Inês Burmester, André Santa-Cruz, Julieta Ramalho, Maria João Regadas, \\ Paulo Gouveia, Guilherme Castro Gomes, Cristina Ângela, Narciso Oliveira, \\ Fernando Mota-Garcia, António Oliveira e Silva
}

\begin{abstract}
Introduction: The majority of parvovirus B19 infections are asymptomatic. In childhood, however, they may present as the fifth disease and in adults their manifestations can vary from mild, non-specific, cold-like symptoms to other forms of presentations. Papular-purpuric gloves and socks syndrome (PPGSS) is an uncommon form of parvovirus B19 infection, characterized by symmetric, pruriginous and painful erythema and edema of feet and hands. Generally, systemic symptoms are usually mild and dissemination to other body regions occurs in only $50 \%$ of the cases. The rash gradually progresses to petechiae and purpura delineating well demarcated "socks" and "gloves" on both feet and hands. The diagnosis is predominantly based on the clinical features. Serologic conversion is not considered as evidence of parvovirus B19 infection and histopathological findings from lesional skin are not specific. There are no definite antiviral
\end{abstract}

Inês Burmester ${ }^{1}$, André Santa-Cruz ${ }^{1,2}$, Julieta Ramalho', Maria João Regadas ${ }^{1}$, Paulo Gouveia ${ }^{1}$, Guilherme Castro Gomes $^{1}$, Cristina Ângela ${ }^{1}$, Narciso Oliveira ${ }^{1}$, Fernando MotaGarcia $^{3}$, António Oliveira e Silva ${ }^{1}$

Affiliations: ${ }^{1} \mathrm{MD}$, Department of Internal Medicine, Braga Hospital, Sete Fontes- São Victor, 4710-243 Braga, Portugal; ${ }^{2} \mathrm{MD}$, Life and Health Sciences Research Institute, School of Health Sciences, University of Minho, Campus Gualtar, 4710057 Braga, Portugal; ${ }^{3} \mathrm{MD}$, Department of Clinical Pathology, Braga Hospital, Sete Fontes- São Victor, 4710-243 Braga, Portugal.

Corresponding Author: Inês Seixas de Sá Burmester, Department of Internal Medicine, Braga Hospital, Sete Fontes- São Victor, 4710-243 Braga, Portugal; Email: inesburmester@gmail.com

Received: 03 October 2015

Accepted: 27 November 2015

Published: 01 March 2016 drugs or vaccines against parvovirus. Patients with PPGSS require only symptomatic therapy. Case Report: We report the case of a 30-year-old female with this characteristic erythema caused by the parvovirus B19. Nevertheless, this case is remarkable because the patient had significant systemic manifestations and an exuberant perineal and oropharyngeal involvement. Further, the erythema assumed a bullous expression that has not been so commonly reported. A biopsy was performed which was unspecific and the diagnosis was confirmed with the serology and molecular detection of the virus in blood sample as well as on mouth swab. Our patient needed treatment to control pain and pruritus, fever was self-limited. Conclusion: A high index of suspicion is essential to diagnose patients with this syndrome. Early recognition can prevent unproductive measures and the good management of this infection.

Keywords: Human parvovirus B19, Parvovirus B19 infection, Papular-purpuric socks and gloves syndrome, Viral infection

\section{How to cite this article}

Burmester I, Santa-Cruz A, Ramalho J, Regadas MJ, Gouveia P, Gomes GC, Ângela C, Oliveira N, MotaGarcia F, eSilva AO. A case report of papular-purpuric gloves and socks syndrome: A manifestation of the parvovirus B19. Int J Case Rep Images 2016;7(3):143148.

Article ID: Z01201603CR10609IB

$* * * * * * * * *$

doi:10.5348/ijcri-201622-CR-10609 


\section{INTRODUCTION}

Parvovirus B19 is a small DNA virus of the Parvoviridae family that causes a worldwide infection [1]. The incubation period varies from 4-21 days and usually affects children and young adults [2]. The majority of the parvovirus B19 infections are asymptomatic, but panoply of manifestations can also occur [3]. In childhood, it may manifest itself as the fifth disease, or megaloeritema, with a macular-papular erythematous rash typically evolving cheeks, trunk and extremities $[1,3]$. In adulthood the disease can vary from mild, non-specific, cold-like symptoms to other uncommon presentations like cutaneous manifestations similar to children's rash, hematological disorders such as transient aplastic crisis and chronic red cell aplasia, rheumatoid manifestations resembling non-erosive polyarthritis and also the so-called gloves-socks syndrome, or papularpurpuric gloves and socks syndrome (PPGSS) $[1,3]$.

The PPGSS is characterized by symmetric, pruriginous and painful erythema and edema of feet and hands that gradually evolves to petechiae and purpura, and may progress to vesicles and bullae with skin desquamation $[3,4]$. The rash typically delineates socks and gloves involving palms and soles and can also involve other areas, such as the perineum region and oral mucosa [3]. Systemic symptoms like fever, arthralgias, asthenia and anorexia can also accompany this condition $[4,5]$.

The diagnosis is based on the dermatological features and confirmed with one of two possible laboratory tests: Parvovirus B19-especific antibody testing and viral DNA testing [6].

There are no specific definite antiviral drugs or vaccines against parvovirus. But generally parvovirus infection is a self-limited disease that resolves in one to three weeks without any treatment [7].

Motivated by the rarity of this syndrome and by the unusual presentation in this patient, the authors decided to report this case of PPGSS.

\section{CASE REPORT}

A 30-year-old female presented to the emergency department complaining of edema and a violaceous, painful and very pruriginous exanthema on both hands and feet. She described that the rash had begun three days before on both soles and progressively extended acquiring a socks pattern (Figure 1). Simultaneously, in both hands the erythema rapidly assumed gloves forms (Figure 2). By the second day, she developed a perineal painful erythematous rash also accompanied by a greenish leucorrhea as well as began to have fever (38$39^{\circ} \mathrm{C}$ ) that responded to antipyretic medication.

Previous medical history of the patient was unremarkable except for an untreated dyslipidemia, a spontaneous abortion at the age of 23 and gestational diabetes during other pregnancy. Her chronic medication included only an oral contraceptive. She had no known allergies. Immunizations were in accord to the national program. She lived with her husband and her 3-year-old son in a suburban area of Portugal and was unemployed. She was monogamous with her husband, did not smoke or used illicit drugs, did not consume any alcohol, had not traveled recently or contact with any diseased person.

On physical examination, the patient was on a good general state of health. She presented symmetrical edema and confluent violaceous macules, papules and pustules on both sides of her hands and feet with well-defined borders delineating "gloves and socks" (Figure 3). The exanthema also developed bullae with skin desquamation on both soles (Figure 4). The perinea region surface was covered with a macular-erythematous and pruritic rash. No ulcers were visible and none satellite lymph nodes were found. The remainder of the physical examination was normal except for the presence of angular cheilitis.

Laboratory studies showed an elevation of the C-reactive protein $(170 \mathrm{mg} / \mathrm{L})$ and a decrease of the platelets count $\left(127 \times 10^{3} / \mathrm{uL}\right)$. Red and white blood cell counts were normal, as well as renal and hepatic function tests and electrolytes. She was admitted to the hospital for clinical monitoring and further diagnostic investigation.

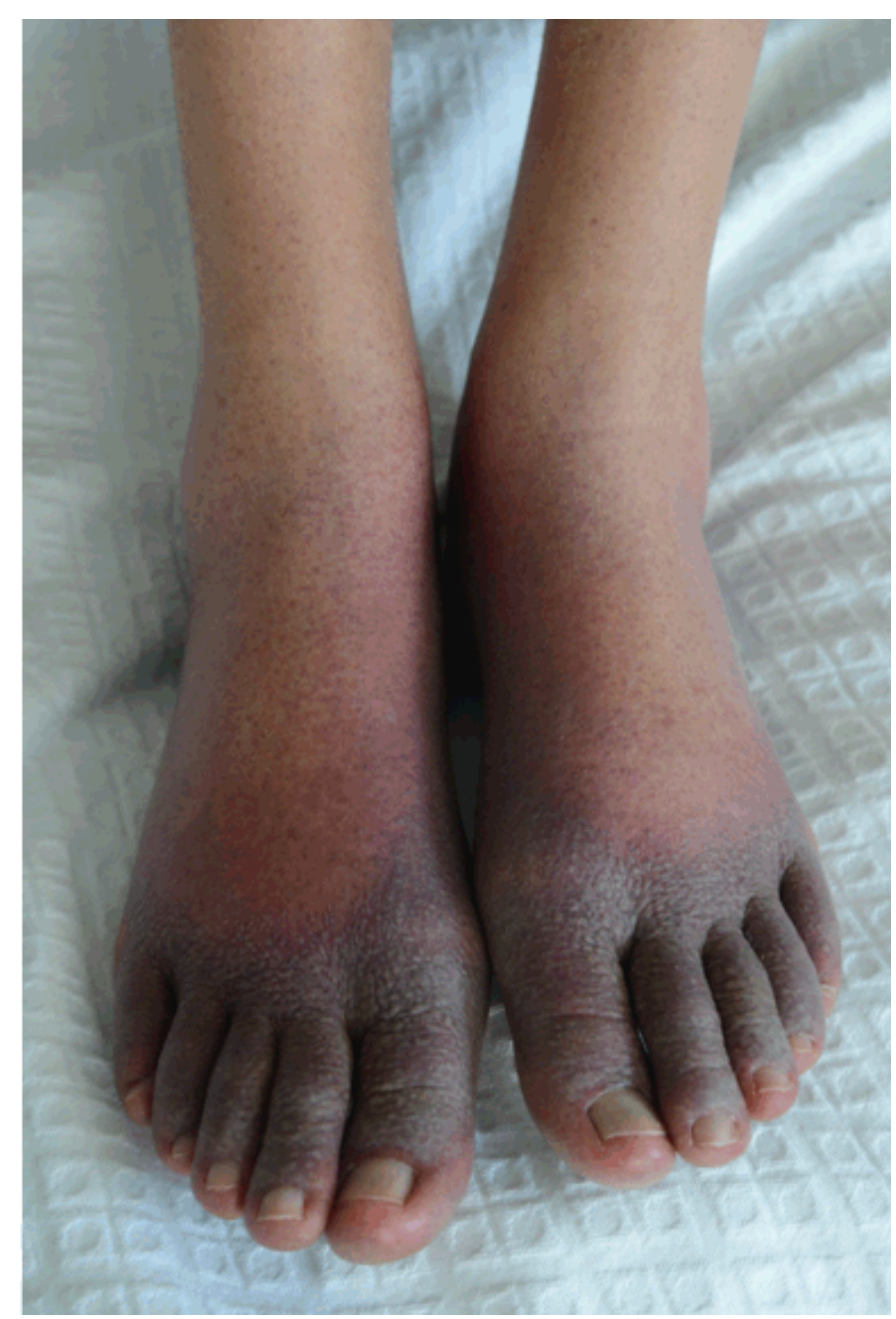

Figure 1: Papular-purpuric exanthema and edema evolving plants in form of socks. 
Empirical antibiotic therapy with doxycycline was started because of the possibility of rickettsiosis, a prevalent disease in Portugal.

On the first day of hospitalization she reported a sensation of burning mouth and difficulty in chewing and swallowing. On the oral exam, the patient had a "pinpoint" enanthema dispersed throughout the palate and the jugal mucosa (Figure 5). She had no ulcers or petechiaes and no involvement of the pharynx or larynx. A swab of the enanthem was made for DNA-virus research.

The patient was evaluated by dermatology on the first day and a steroid therapy (prednisolone $1 \mathrm{mg} / \mathrm{kg}$ per day) was started for suspected vasculitis. At that time a cutaneous biopsy was performed.

Additional laboratory studies were requested with normal $\mathrm{C}_{3}$ and $\mathrm{C}_{4}$ complement, cryoglobulins and protein-electrophoresis. The erythrocyte sedimentation rate was $48 \mathrm{~mm} / \mathrm{h}$ and the immunological study was also normal (antinuclear, antineutrophil, anti-DSDNA, antiphospholipid and anticardiolipin antibodies). Serologic testing for viral hepatitis A, B and C, syphilis, rickettsia, Epstein-Barr virus, cytomegalovirus and rubella excluded recent infection. HIV serology was negative. ELISA tests for herpes virus and for parvovirus

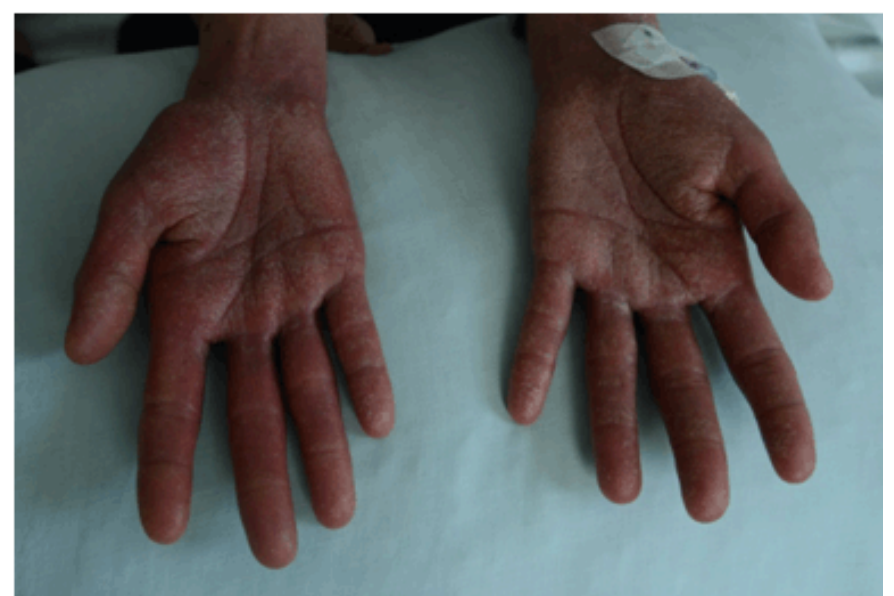

Figure 2: Papular-purpuric exanthema evolving palms in form of gloves.

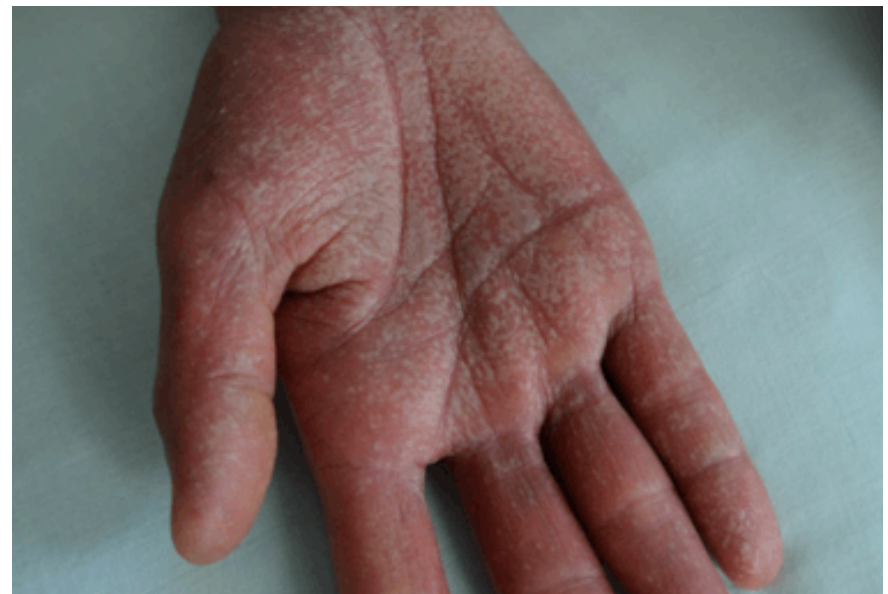

Figure 3: Details of the palms emphasizing the pustules.

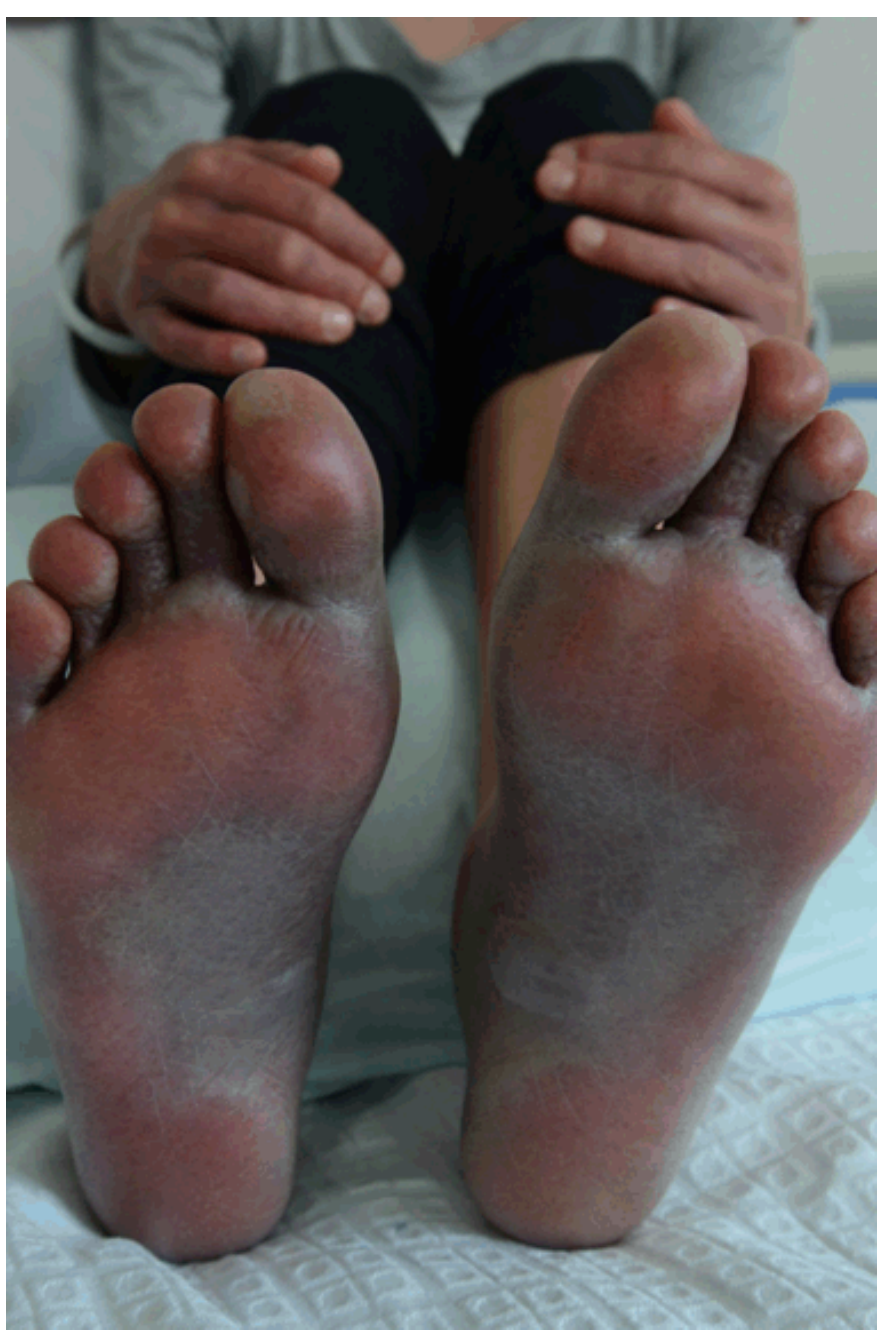

Figure 4: Details of the exanthema with the formation of bullae.

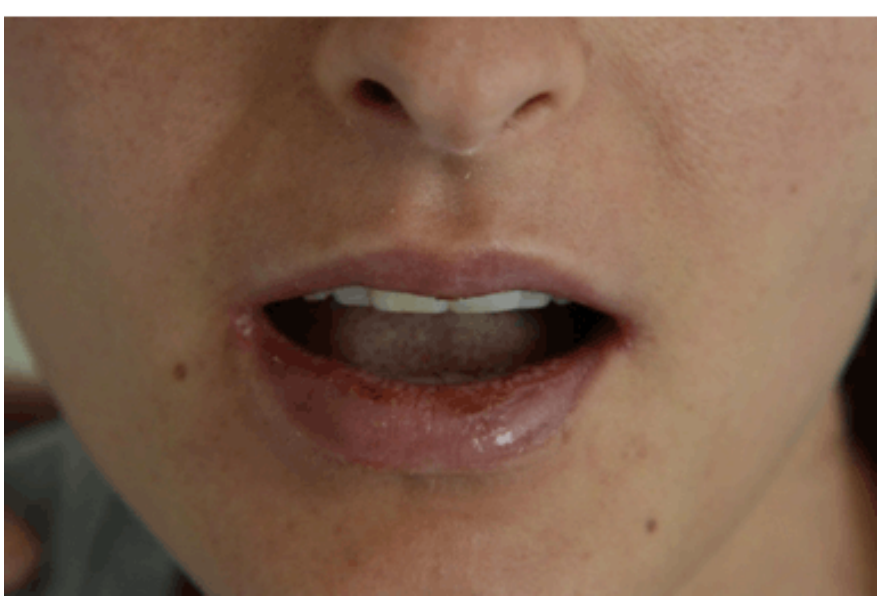

Figure 5: "Pinpoint" oropharyngeal enanthema.

B19 were positive for IgM and IgG antibodies. The presence of parvovirus B19 DNA was then confirmed with blood polymerase-chain-reaction (PCR). Enterovirus, coxsackie included, were also excluded with PCR. Furthermore, the result of the oropharyngeal enanthem swab came out two days later and confirmed the 
parvovirus B19 infection. The skin biopsy results was not specific, and revealed "mild acanthosis and keratinocyte apoptosis in the epidermis and capillary dilatation with perivascular infiltrate consisting in lymphocytes, histiocytes and eosinophils in the dermis".

By the time of diagnosis, on the third day of hospitalization, the enanthems improved and the patient was able to eat. The cutaneous lesions became dryer and less pruritic. Doxycycline and prednisolone therapy were discontinued. The platelets count returned to normal and the C-reactive protein acquired a descending profile. Consequently, the patient was discharged home only with antihistamine therapy, on the seventh day of hospitalization.

In the follow-up consultation, one month later, a complete remission of the lesions on both perineal and oropharyngeal enanthems and the normalization of all analytical parameters were verified. The patient was able to return to her daily life.

\section{DISCUSSION}

Parvovirus B19 affects mostly children and young adults, has a high index of infectivity and is more frequent in winter and spring [1]. We report a case occurred on spring of a female patient with the PPGSS who had a three-year-old boy who recently started attending a nursery school.

The PPGSS in this patient assumed the characteristic papular-purpuric pruriginous eruption affecting hands and feet. Nevertheless, this case is remarkable because of the systemic manifestations and the exuberant perineal and oropharyngeal involvement. Generally, systemic symptoms are usually mild and patients may experience low-grade fever (52\%), fatigue (20\%), myalgias (16\%), anorexia (16\%), lymphadenopathy (16\%) and artralgias (12\%). Dissemination to other body regions occurs in only $50 \%$ of the cases $[8,9]$. Bullous skin lesions have not been so commonly reported [8]. In this case, when certain skin areas started to reveal bullae, our concern increased towards the possibility of developing Lyelllike syndrome characteristics or more severe infection complications. When the diagnosis was made that risk was considered lower since this disease is usually selflimited with resolution of the exanthema from one to three weeks $[1,7,8]$. Very occasionally, especially in cases of immunosuppression, the exanthema can persist for months [8] or even reappear without any particular trigger [10].

The rarity and unfamiliarity with this presentation of this disease led us to consider a wide range of alternative diagnosis, with multiple tests and exams being performed. PPGSS differential diagnosis should include other infections with cutaneous involvement, vasculitis, hematologic and rheumatic diseases [4]. Other viral infections such as Coxsackie B6 virus, human herpes virus 6 or 7, hepatitis B, Epstein-Barr, cytomegalovirus, measles and rubella virus as well as the Arcanobacterium haemolyticum infection have been described as PPGSS [4]. Additionally, the trimethoprim/sulfamethoxazole [11] can also be related to this syndrome.

The detection of specific immunoglobulin $\mathrm{M}$ is helpful for the diagnosis. Its peak occurs within the first week, declines during the four subsequent weeks [1] and can be detectable until three months after infection [3]. Immunoglobulin $\mathrm{G}$ testing is not useful because it only indicates previous infection or immunity $[1,3,6]$. In the initial acute phase, the polymerase chain reaction is recommended to detect DNA virus, which can be detected even with very low viral load $[1,2]$. However, normally there are no viruses in circulation when the symptoms emerge [3]. On average, the viremia period lasts 1 to 2 days, in general 7-9 days after exposure $[1,6]$.

In this case, IgG and IgM positivity to herpes virus and parvovirus B19 were observed. A cross reaction with other viruses is frequently found in recent parvovirus B19 infections, producing false-positive reactions in a variety of other infection diseases, specially Herpes virus and Epstein-Barr, virus infection [12].

As a consequence of a seroprevalence rate of 20-80\%, in the American and European adult population [1], and the cross-reactions for the immunoglobulin M antibody class, serologic conversion is not considered as evidence of parvovirus B19 infection [8]. In our patient, the molecular detection of the virus in blood sample as well as on mouth swab strongly supports a causative role of the parvovirus B19 in PPGSS. In our hospital, the polymerase chain reaction is only qualitative and consequently we did not have access to the viral load. Nevertheless, with the favorable evolution of our patient and the positivity to the parvovirus B19, we thought it was not necessary.

Histopathological findings from skin lesions are not specific and therefore they are not useful to diagnose PPGSS. Thus, molecular detection of DNA virus in skin biopsy can be made, establishing the diagnosis [8].

Patients with PPGSS require only symptomatic therapy for fever, pain and pruritus. Corticosteroid therapy is not indicated because immunosuppressive therapy can promote the persistency of the virus [4].

We would like to highlight as particular strengths in this case, the epidemiology (seasonability and patient's young child) and the rare but characteristic erythema. As limitations we emphasize the extreme rarity and unfamiliarity of this syndrome that can lead to misdiagnosis due to the huge variety of differential diagnosis. The misconduct of this disease can mask the clinic, lead to prolongation or even complications of the syndrome. In our particular case, the doxycycline and the prednisolone therapy could have been avoided if we knew the syndrome.

\section{CONCLUSION}

A high index of suspicion is essential to diagnose patients with this syndrome. Early recognition can prevent 
unproductive measures and the good management of this infection.

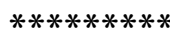

\section{Author Contributions}

Inês Burmester - Substantial contributions to conception and design, Acquisition of data, Analysis and interpretation of data, Drafting the article, Revising it critically for important intellectual content, Final approval of the version to be published

André Santa-Cruz - Analysis and interpretation of data, Revising it critically for important intellectual content, Final approval of the version to be published

Julieta Ramalho - Analysis and interpretation of data, Revising it critically for important intellectual content, Final approval of the version to be published

Maria João Regadas - Analysis and interpretation of data, Revising it critically for important intellectual content, Final approval of the version to be published

Paulo Gouveia - Analysis and interpretation of data, Revising it critically for important intellectual content, Final approval of the version to be published

Guilherme Castro Gomes - Analysis and interpretation of data, Revising it critically for important intellectual content, Final approval of the version to be published Cristina Ângela - Analysis and interpretation of data, Revising it critically for important intellectual content, Final approval of the version to be published

Narciso Oliveira - Analysis and interpretation of data, Revising it critically for important intellectual content, Final approval of the version to be published

Fernando Mota-Garcia - Analysis and interpretation of data, Revising it critically for important intellectual content, Final approval of the version to be published António Oliveira e Silva - Analysis and interpretation of data, Revising it critically for important intellectual content, Final approval of the version to be published

\section{Guarantor}

The corresponding author is the guarantor of submission.

\section{Conflict of Interest}

Authors declare no conflict of interest.

\section{Copyright}

(C) 2016 Inês Burmester et al. This article is distributed under the terms of Creative Commons Attribution License which permits unrestricted use, distribution and reproduction in any medium provided the original author(s) and original publisher are properly credited. Please see the copyright policy on the journal website for more information.

\section{REFERENCES}

1. Araújo F, Koch MC, Monteiro F, Araújo AR. Parvovirus B19 infection. [Article in Portuguese]. Acta Med Port 1999 Apr-Jun;12(4-6):195-202.
2. Martínez GMJ, Elgueta NA. A family outbreak of parvovirus B19 atypical exanthemas: report of two cases. Rev Med Chil 2008 May;136(5):620-3.

3. Servey JT, Reamy BV, Hodge J. Clinical presentations of parvovirus B19 infection. Am Fam Physician 2007 Feb 1;75(3):373-6.

4. Bello S, Fanizzi R, Bonali C, Serafino L, Terlizzi N, Lapadula G. Papular-purpuric gloves and socks syndrome due to parvovirus B19: a report of two simultaneous cases in cohabitant families. Reumatismo 2013 Mar 28;65(1):40-5.

5. Hashimoto H, Yuno T. Parvovirus B19-associated purpuric-petechial eruption. J Clin Virol 2011 Nov;52(3):269-71.

6. Martins C, Gonçalo M, Mariano A, Poiares-Baptista A. Papular-purpuric gloves and socks syndrome. J Eur Acad Dermatol Venereol 2002;16(1):91-3.

7. Heckler GT, Dal Ri NM, Almeida Júnior HL. Case for diagnosis. Papular-purpuric gloves and socks syndrome. An Bras Dermatol 2012 SepOct;87(5):793-4.

8. Frühauf J, Massone C, Müllegger RR. Bullous papular-purpuric gloves and socks syndrome in a 42-year-old female: molecular detection of parvovirus B19 DNA in lesional skin. J Am Acad Dermatol 2009 Apr;60(4):691-5.

9. Smith PT, Landry ML, Carey H, Krasnoff J, Cooney E. Papular-purpuric gloves and socks syndrome associated with acute parvovirus B19 infection: case report and review. Clin Infect Dis 1998 Jul;27(1):1648.

10. Sklavounou-Andrikopoulou A, Iakovou M, Paikos S, Papanikolaou V, Loukeris D, Voulgarelis M. Oral manifestations of papular-purpuric 'gloves and socks' syndrome due to parvovirus B19 infection: the first case presented in Greece and review of the literature. Oral Dis 2004 Mar;10(2):118-22.

11. van Rooijen MM, Brand CU, Ballmer-Weber BK, Yawalkar N, Hunziker TK. Drug-induced papularpurpuric gloves and socks syndrome. [Article in German]. Hautarzt 1999 Apr;50(4):280-3.

12. Berth M, Bosmans E. Acute parvovirus B19 infection frequently causes false-positive results in EpsteinBarr virus- and herpes simplex virus-specific immunoglobulin $\mathrm{M}$ determinations done on the Liaison platform. Clin Vaccine Immunol 2009 Mar;16(3):372-5. 
Access full text article on other devices

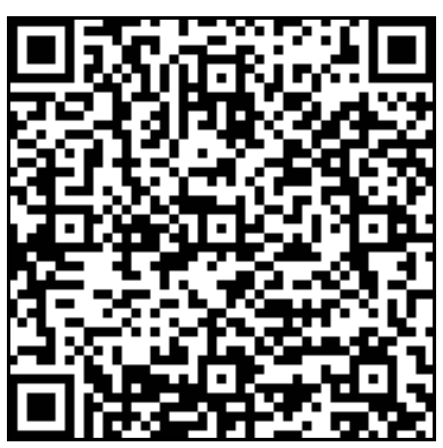

Access PDF of article on other devices

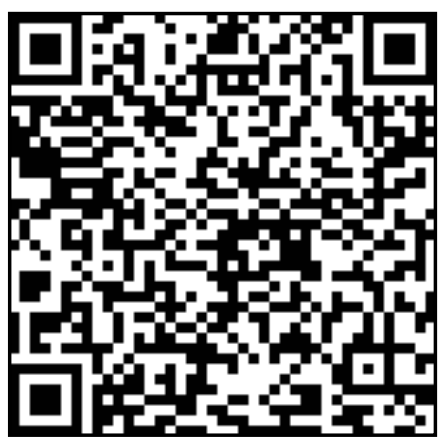




\title{
Edorium Journals: An introduction
}

\author{
Edorium Journals Team
}

\section{About Edorium Journals}

Edorium Journals is a publisher of high-quality, open access, international scholarly journals covering subjects in basic sciences and clinical specialties and subspecialties.

\section{Invitation for article submission}

We sincerely invite you to submit your valuable research for publication to Edorium Journals.

\section{But why should you publish with Edorium Journals?}

In less than 10 words - we give you what no one does.

\section{Vision of being the best}

We have the vision of making our journals the best and the most authoritative journals in their respective specialties. We are working towards this goal every day of every week of every month of every year.

\section{Exceptional services}

We care for you, your work and your time. Our efficient, personalized and courteous services are a testimony to this.

\section{Editorial Review}

All manuscripts submitted to Edorium Journals undergo pre-processing review, first editorial review, peer review, second editorial review and finally third editorial review.

\section{Peer Review}

All manuscripts submitted to Edorium Journals undergo anonymous, double-blind, external peer review.

\section{Early View version}

Early View version of your manuscript will be published in the journal within 72 hours of final acceptance.

\section{Manuscript status}

From submission to publication of your article you will get regular updates (minimum six times) about status of your manuscripts directly in your email.

\section{Our Commitment}

\section{Six weeks}

You will get first decision on your manuscript within six weeks (42 days) of submission. If we fail to honor this by even one day, we will publish your manuscript free of charge.

\section{Four weeks}

After we receive page proofs, your manuscript will be published in the journal within four weeks (31 days). If we fail to honor this by even one day, we will publish your manuscript free of charge and refund you the full article publication charges you paid for your manuscript.

\section{Most Favored Author program}

Join this program and publish any number of articles free of charge for one to five years.

\section{Favored Author program}

One email is all it takes to become our favored author. You will not only get fee waivers but also get information and insights about scholarly publishing.

\section{Institutional Membership program}

Join our Institutional Memberships program and help scholars from your institute make their research accessible to all and save thousands of dollars in fees make their research accessible to all.

\section{Our presence}

We have some of the best designed publication formats. Our websites are very user friendly and enable you to do your work very easily with no hassle.

\section{Something more...}

We request you to have a look at our website to know more about us and our services.

We welcome you to interact with us, share with us, join us and of course publish with us.

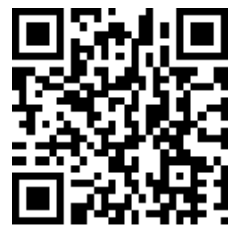

Edorium Journals: On Web

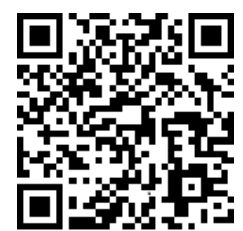

CONNECT WITH US
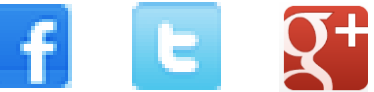